\title{
Introducción: \\ Riesgos y amenazas para la seguridad humana
}

Cuando terminó la Segunda Guerra Mundial, el mundo asistía a un nuevo paradigma con el que construir la sociedad internacionales, desde parámetros más inclusivos. Nace la Organización de las Naciones Unidas con el objetivo de organizar una nueva sociedad, basada en el arreglo pacífico de las controversias y en la limitación del uso de la fuerza, como principales focos de interés.

Sin embargo, la realidad truncó los buenos deseos de los creadores de la ONU y sus postulados han entrado en crisis. Esta crisis no es sólo de organización sino de respuestas porque la dignidad del ser humano se ha hecho central en todos los debates de la política internacional. Han cambiado los medios, los contextos, los riesgos, las amenazas y, consecuentemente, hay que dar respuestas integradas y multidimensionales que ofrezcan soluciones a largo plazo. Existen, en consecuencia, nuevas amenazas que afrontar. Junto a los tradicionales riesgos y amenazas, como los conflictos armados, las catástrofes naturales, los enfrentamientos políticos, surgen otras de dimensión transnacional, que se ven potenciados por situaciones complejas como los desequilibrios demográficos, la pobreza, la desigualdad, la inestabilidad económica. De esta manera hay una vulnerabilidad antes desconocida y a nivel planetario.

El papel del derecho, como instrumento social de organización y de convivencia se hace imprescindible y, en un entorno internacional, el Derecho internacional público debe dar respuestas fiables y eficaces. Por supuesto, sería irrisorio que el Derecho, como disciplina, pretendiera contar con todas las explicaciones y con todas las soluciones. Irremisiblemente se van a necesitar de otras disciplinas que permitan comprender las distintas situaciones a las que el derecho debe dar respuesta. Por ello, las aproximaciones metodológicas pluridisciplinares serán esenciales en este debate.

Contamos, pues, con una nueva escenografía en la que hay actores diversos, actos sucesivos, acompañamientos variados y circunstancias diversas que harán complejo el análisis.

A pesar de ello, un pequeño grupo de expertos, de investigadores se han tomado en serio esta escenografía y cada uno de ellos se ha atrevido con algunos de los riesgos y amenazas de nuestro tiempo. Desde luego, era imposible abordarlos y, por ello, hemos seleccionado, no los más importantes porque todos lo son, sino aquellos más próximos a las distintas líneas de investigación de cada investigador.

Hemos sido conscientes de la vulnerabilidad, incluso conceptual, en la que vive hoy día el Estado, a quien, en primer lugar se le exige los medios para protegerse a sí mismo y, por tanto, a su población pero que, a veces, no 
es ya capaz de articular por sí sólo, un sistema de protección de sus intereses $\mathrm{y}$, ni siquiera, un sistema de autoabastecimiento de sus necesidades básicas y primarias, mucho menos de las superfluas o secundarias, tan importante en nuestras sociedades opulentas.

Por tanto, la cooperación va a ser la regla para poder afrontar todos los riesgos y amenazas que se ciñen sobre nuestra sociedad. Ni siquiera los Estados más poderosos pueden enfrentarse solos a estos nuevos escenarios. La cooperación, pues, se convierte en la piedra angular ante estos riesgos y amenazas.

Para que la cooperación sea eficaz y eficiente, debe estar institucionalizada y para ello, disponemos de organizaciones internacionales óptimas, como la Organización de las Naciones Unidas y toda su red de órganos, organismos y establecimientos públicos internacionales que deberían permitir una respuesta lo más inmediata posible. ¡Claro que para ello los Estados deberían renunciar a su liderazgo de lo humanitario!

Algunos de los riesgos y amenazas clásicos se han sofisticado o se han intensificado convirtiéndose en riesgos y amenazas potencialmente mucho más destructivos que los de antaño. Por ejemplo, siempre ha habido desastres naturales, e incluso industriales, pero sus efectos estaban limitados y sus potenciadores eran reducidos. Ahora, las catástrofes medioambientales o industriales pueden asociarse a la pobreza, a la miseria pero también a los usos irracionales de los recursos naturales, a la alta tecnología, a la utilización de métodos terroristas contra objetivos civiles que contienen fuerzas peligrosas o nocivas para la salud del ser humano.

El conocimiento científico siempre fue un activo del ser humano. Y lo sigue siendo. Pero la perversión puede hacer que lo que es un potencial salvador del ser humano se convierta en una de sus mayores amenazas. Por ello dedicamos varios capítulos a estos riesgos y amenazas. Entre ellos, a la cada vez más sofisticada tecnología de guerra, que hace casi irreconocible el marco de protección desarrollado con las Convenciones de Ginebra de 1949 y sus Protocolos Adicionales de 1977. Igualmente el uso de internet, gran herramienta de comunicación, que ha acercado pueblos y personas hasta límites insospechados pero que, también es un potencial para los terroristas, los pederastas, los servicios secretos, el reclutamiento ilegal, el comercio de sustancias prohibidas, etc. etc. Por último, en esta marco de los riesgos y amenazas de las altas tecnologías, nos ha merecido un apartado especial la biotecnología, también por sus potencialidades.

Por otro lado, también estamos asistiendo a un cambio en los parámetros de las migraciones. Sigue habiendo muchos movimientos migratorios voluntarios pero la mayoría y, sobre todo, los flujos masivos, son involuntarios, es decir, provocados por las guerras, los conflictos étnicos, el hambre, las calamidades 
climáticas y pronto lo serán por el agua, por las enfermedades, por la presión religiosa, por el control de la energía...

Muchos de estos flujos, como he dicho, vienen precedidos por situaciones de catástrofes medioambientales, muchas de ellas provocadas por el cambio climático, que como se ha dicho hasta la saciedad, es la alteración del clima como consecuencia de la actividad humana. Ello incide, sin duda, en la ganadería y la agricultura, en la frecuencia e intensidad de las precipitaciones de lluvia, en la acidificación de las aguas, en la desaparición de la cobertura vegetal y, en definitiva, en la vida del ser humano. Ello conlleva riesgos y amenazas bien visibles ya en la actualidad, poniendo en tela de juicio, incluso, la propia alimentación del ser humano.

El crimen organizado es otro elemento que hay que tener en cuenta en nuestro análisis. De esta forma, lo hemos analizado desde dos perspectivas distintas: desde el control de la droga y desde un marco de prevención, represión y sanción del terrorismo.

Aun siendo consciente de cuantos temas deberían haberse abordado en este monográfico, las limitaciones de espacio, de tiempo y de capacidad, me han hecho reducirlo a los siguientes temas:

"Re-Aproximaciones y Posibles Aplicaciones del Concepto de Seguridad Humana", por Waldimeiry Corrêa da Silva, Directora del Departamento de Relaciones Internacionales de la Universidad Loyola de Andalucía, y Roberta Silva Machado, Doctoranda en el Programa de Doctorado en Ciencia Política, área Estudios Internacionales, en el Instituto de Filosofía y Ciencias Humanas de la Universidade Estadual de Campinas (UNICAMP), Brasil. Becaria CAPES, Brasil. Profesora de las Faculdades Campinas (FACAMP), Brasil.

"Estrategia Internacional para la Seguridad Humana en los Desastres Naturales", por la Dra. Helena Torroja Mateu, Profesora Titular de Derecho Internacional Público y Relaciones Internacionales de la Universidad de Barcelona.

“Altas Tecnologías, Conflictos Armados y Seguridad Humana”, por la Dra. Elena del Mar García Rico, Profesora Titular de Derecho Internacional Público y Relaciones Internacionales, Universidad de Málaga.

"El Derecho a la Alimentación ante los Riesgos del Futuro", por Miguel Ángel Martín López, Profesor Titular (acreditado) de Derecho Internacional Público y Relaciones Internacionales, Universidad de Sevilla. 
"El Cambio Climático como Riesgo y Amenaza para la Seguridad: Derivaciones en el Desarrollo del Régimen Jurídico Internacional en Materia de Clima", por la Dra. Rosa Giles Carnero, Profesora Titular de Derecho Internacional Público y Relaciones Internacionales, Universidad de Huelva.

"Flujos Masivos de Población y Seguridad Humana. La Crisis de Personas Refugiadas en el Mediterráneo", por la Dra. Nuria Arenas Hidalgo, Profesora Titular de Derecho Internacional Público y Relaciones Internacionales y Miembro del Consejo Editorial del Refugee Law Reader. Centro de Estudios de Migraciones. Universidad de Huelva

“ 'If Ya Wanna End War and Stuff, You Gotta Sing Loud'-A Survey of the Provisional Agreement between FARC and Colombia on Illicit Drugs", por el Dr. Francesco Seatzu, Catedrático de Derecho Internacional de la Università degli Study di Cagliari (Italia).

"¿Qué seguridad? Riesgos y Amenazas de Internet en la Seguridad Humana", por el Dr. Rafael Rodríguez Prieto, Profesor Titular de Filosofía del Derecho de la Universidad Pablo de Olavide.

"Seguridad Humana ante Nuevos Riesgos Biotecnológicos, entre la 'cientificación' y la 'politización'”, por el Dr. Justo Corti Varela, Profesor Contratado Doctor de la Universidad San Pablo CEU.

"La Lucha contra el Terrorismo en la Unión Europea desde una Perspectiva Procesal", por el Dr. Ángel Tinoco Pastrana, Profesor Titular (acreditado) de Derecho Procesal, Universidad de Sevilla.

No podría terminar esta introducción sin mencionar el marco en el que se han desarrollado las investigaciones. El Ministerio de Economía y Competitividad español concedió una Red de Excelencia sobre "Los actuales desafíos del Derecho Internacional", aprobada por resolución de concesión de 27 de noviembre de 2015 de la Secretaría de Estado de Investigación, Desarrollo e Innovación, de ayudas correspondientes a la convocatoria 2015 de las Acciones de dinamización "Redes de Excelencia", del Programa Estatal de Investigación Científica y Técnica de Excelencia, Subprograma Estatal de Generación de Conocimiento, en el marco del Plan Estatal de Investigación Científica y Técnica y de Innovación 2013-2016 (DER15-69273-RED).

Igualmente el mismo Ministerio de Economía y Competitividad español concedió un proyecto de Excelencia sobre "Las Respuestas del Derecho Internacional y Europeo a los Nuevos Riesgos y Amenazas contra la Seguridad 
Humana", aprobado por resolución de concesión de la Secretaría de Estado de Investigación, Desarrollo e Innovación, de ayudas correspondientes a la convocatoria 2015 de "Proyectos de Excelencia", del Programa Estatal de Investigación Científica y Técnica de Excelencia, Subprograma Estatal de Generación de Conocimiento, en el marco del Plan Estatal de Investigación Científica y Técnica y de Innovación 2013-2016 (DER2015-65906-P).

Muchos de los investigadores que han contribuido a este monográfico han realizado sus contribuciones en el marco de los citados proyectos.

Pablo Antonio Fernández-Sánchez Catedrático de Derecho Internacional Público y Relaciones Internacionales UNIVERSIDAD DE SEVILLA 
